\title{
Digestibilidade Aparente da Energia e Nutrientes de Alimentos Convencionais e Alter- nativos para a Tilápia do Nilo (Oreochromis niloticus, L.)
}

\author{
Wilson Rogério Boscolo ${ }^{1}$, Carmino Hayashi ${ }^{2}$, Fábio Meurer ${ }^{3}$
}

\begin{abstract}
RESUMO - O experimento foi conduzido com o objetivo de avaliar os coeficientes de digestibilidade aparente (CDa) da matéria seca (MS), energia bruta (EB) e proteína bruta (PB) do farelo de soja (FS), milho (MO), trigo (TG), farelo de trigo (FT), milheto (MT), triticale (TC), farinha de varredura de mandioca (FM) e óleo de soja (OS) para tilápia do Nilo da linhagem tailandesa. Foram utilizados 100 animais revertidos sexualmente, com peso médio de 37,61 \pm 4,98 g distribuídos em dois tanques de alimentação de 500L e coleta de fezes pelo sistema modificado de Guelph em dois aquários (150 L cada). A determinação dos CDa foi realizada pelo método indireto, sendo utilizado como indicador $0,1 \%$ de óxido de cromo $\left(\mathrm{Cr}_{2} \mathrm{O}_{3}\right)$ incorporado à ração. Os CDa para a MS, PB e EB foram de 65,49, 89,58 e 71,38 para FS; 73,22, 93,40 e 76,63 para MO; 86,51, 96,30 e 87,07 para TG; 66,79, 91,00 e 68,81 para FT; 77,96, 94,91 e 89,12 para MT; 68,51, 94,78 e 80,55 TC; 91,11,97,52 e 91,40\% para FV, respectivamente; e para a EB do OS o CDa foi 89,85\%, apresentando valores de proteína (\%) e energia (kcal/kg) digestíveis de 42,19 e 3057,63 para FS; 7,18 e 3037,03 para MO; 11,01 e 3423,66 para TG; 13,44 e 2825,88 para FT; 13,88 e 3755,55 para MT; 13,74 e 3230,69 para TC; 1,76 e 3280,09 para FM, respectivamente, e 8485,28 kcal/kg de ED para o OS. Os resultados demonstraram que a tilápia do Nilo utiliza eficientemente a energia e proteína desses ingredientes. Os valores de energia e proteína digestíveis devem ser utilizados para elaborar rações completas.
\end{abstract}

Palavras-chave: alimentos, digestibilidade aparente, tilápia do Nilo, Oreochromis niloticus

\section{Apparent Digestibility of the Energy and Nutrients of Conventional and Alternatives Foods for Nile Tilapia (Oreochromis niloticus)}

\begin{abstract}
The trial aimed to evaluate the apparent strain digestibility coefficients (CDa) of dry matter (MS), gross energy (EB) and crude protein (PB) of soybean meal (FS), corn (MO), wheat (TG), wheat meal (FT), millet pearl (MT), triticale (TC), cassava meal (FM) and soybean oil (OS) of Nile tilapia fingerlings of Thai. One hundred sexual reverted animals were used, with a mean weight of $37.61 \pm 4.98 \mathrm{~g}$, distributed in two alimentation 500L mansory tanks and feces collect in modified Guelph system in two $150 \mathrm{~L}$ aquariums. $\mathrm{CDa}$ was determined by an indirect method, with $0.1 \%$ chromic oxide $\left(\mathrm{Cr}_{2} \mathrm{O}_{3}\right)$ as marker. CDa of MS, PB and EB was $65.49,89.58$ and 71.38 for FS; $73.22,93.40$ and 76.63 for MO; 86.51, 96.30 and 87.07 for TG; 66.79, 91.00 and 68.81 for FT; $77.96,94.91$ and 89.12 for MT; 68.51, 94.78 and 80.55 for TC; $91.11,97.52$ and $91.40 \%$ for FM, respectively, and for EB of soybean oil $89.85 \%$, the values of digestible protein (\%) and energy ( $\mathrm{kcal} / \mathrm{kg}$ ) were 42.19 and 3057.63 for FS; 7.18 and 3037.03 for MO; 11.01 and 3423.66 for TG; 13.44 and $2825.88 \mathrm{FT}$; 13.88 and $3755.55 \mathrm{MT}$; 13.74 and 3230.69 for TC; 1.76 and 3280.09; for FM and $8485.28 \mathrm{kcal} / \mathrm{kg}$ of energy digestible for OS. The results showed that the protein and energy of these foods are efficiently used by Nile tilapia. To formulate complete diets the digestible protein and energy values must be used.
\end{abstract}

Key Words: apparent digestibility, foods, Nile tilapia, Oreochromis niloticus

\section{Introdução}

As tilápias são naturais da África, Israel e Jordânia e devido a seu potencial para a aqüicultura, tiveram sua distribuição expandida nos últimos cinqüenta anos. Pelo fato de ser uma espécie apropriada para a piscicultura de subsistência, nos países em desenvolvimento (Lovshin, 1997), e devido à sua importância na aqüicultura, muitos aspectos da nutrição desta espécie são estudados (Degani \& Revach, 1991). A tilápia do Nilo (Oreochromis niloticus) apresenta hábito alimentar onívoro e utiliza eficientemente os carboidratos da dieta (Viola \& Arieli, 1983; Anderson et al., 1984; Degani \& Revach, 1991; Shiau, 1997).

O alto custo das rações, mais de $50 \%$ do custo de produção da aqüicultura intensiva (El-Sayed, 1999), tem levado à pesquisa de alimentos alternativos. $\mathrm{O}$ conhecimento da digestibilidade da energia e nutrien-

\footnotetext{
${ }^{1}$ Professor MSc. do curso de Engenharia de Pesca/UNIOESTE-Toledo-PR, Programa de Pós-Graduação em Zootecnia/Universidade Estadual de Maringá. Av. Colombo, 5790, Jardim Universitário, Maringá - Paraná; E.mail: wrboscolo@bol.com.br

2 Professor titular do Depto. de Biologia/UEM. E.mail: chayashi@uem.br

${ }^{3}$ Zootecnista Msc, Pós-graduando do Programa de Pós-Graduação em Zootecnia/Universidade Estadual de Maringá E.mail: f-meurer@bol.com.br
} 
tes dos alimentos permitem a formulação das rações de mínimo custo que atendam as exigências nutricionais dos animais (Sullivan \& Reigh, 1995; McGoogan \& Reigh, 1996; Aksnes \& Opstvedt, 1998).

Estudos de digestibilidade são importantes para o desenvolvimento de rações para o uso na aqüicultura (Jones \& De Silva, 1997), sendo um dos aspectos mais relevantes para avaliar a capacidade de uma determinada espécie em utilizar os nutrientes de um determinado alimento (Hanley, 1987), além de ser um indicador potencial da energia e nutrientes disponíveis para o crescimento, mantença e reprodução do animal, bem como dos níveis de nutrientes indigestíveis para avaliação de resíduos aquaculturais (Cho, 1993).

Estimativas da digestibilidade têm sido prioridade para a nutrição na aqüicultura, tanto para avaliar ingredientes ou a qualidade de rações completas (Sadiku \& Juancey, 1995). Estudos têm revelado diferentes disponibilidades de energia para as diferentes espécies, de acordo com as diferenças na fisiologia da digestão (Degani et al., 1997a).

O coeficiente de digestibilidade pode ser calculado por dois métodos, o indireto, em que a coleta de excretas é parcial, utilizando-se indicadores como substância referência, e o direto, no qual a quantificação do alimento ingerido e a coleta de excretas são totais (Noüe \& Choubert, 1986; Pezzato et al., 1988; NRC, 1993). Tampouco, o método direto ou o indireto consideram a inclusão de material endógeno na excreta. No entanto, os dados de digestibilidade obtidos atualmente estão aparentemente bastante próximos aos valores verdadeiros (NRC, 1993).

De acordo com Morales et al. (1999), a quantificação do alimento consumido e a coleta total das fezes é dificultada pelo meio aquático, por isso, usa-se preferencialmente o método indireto de determinação de digestibilidade.

O óxido crômico é usado como indicador inerte em experimentos de digestão e balanço de nutrientes para animais domésticos, e este indicador tem sido utilizado com sucesso para a determinação da digestibilidade aparente em peixes (Smith \& Lovell, 1973; NRC, 1993; Degani et al., 1997a). Em estudos utilizando óxido crômico como indicador, o nutriente componente da dieta é calculado por intermédio da taxa do indicador para o nutriente no alimento e nas fezes (Hanley, 1987).

Entre os produtos e subprodutos convencionais e alternativos disponíveis no Brasil, destacam-se o farelo de soja (FS), milho (MO), trigo (TG), farelo de trigo (FT), óleo de soja (OS), triticale (TC), milheto (MT) e farinha de varredura de mandioca (FM). Poucos são os trabalhos sobre a digestibilidade destes alimentos para os peixes, principalmente com relação aos alternativos. Devido à grande diversidade de espécies, as investigações com peixes, apesar de acumularem décadas, ainda se apresentam escassas quando comparadas com outras espécies zootécnicas (Pezzato, 1999).

Muitas vezes, para a formulação de rações para peixes, são utilizados valores de proteína e energia bruta ou digestíveis de alimentos determinados para outros animais (Aksnes \& Opstvedt, 1998), o que não é nutricionalmente adequado, além de provocar maior impacto tanto à criação quanto ao ambiente, pois os nutrientes não digeridos e absorvidos serão excretados (Sugiura et al., 1998).

O presente trabalho teve por objetivo determinar os coeficientes de digestibilidade aparente (CDa) da matéria seca $(\mathrm{MS})$, proteína $(\mathrm{PB})$ e energia $(\mathrm{EB})$ de alimentos convencionais (milho, óleo de soja e farelos de trigo e soja) e alternativos (farinha de varredura de mandioca, milheto, triticale e trigo integral) para a tilápia do Nilo (Oreochromis niloticus) de linhagem tailandesa.

\section{Material e Métodos}

O experimento foi conduzido durante o período de novembro de 1999 a fevereiro de 2000 . Foram utilizadas 100 tilápias $(O$. niloticus $)$ revertidas de linhagem tailandesa, com peso vivo médio de 37,61 $\pm 4,98 \mathrm{~g}$, distribuídas em dois tanques de alimentação de 500L, onde ficavam durante o período de adaptação e também durante o dia no período de coleta.

Para a coleta das fezes, os animais foram alojados em tanques de digestibilidade com forma afunilada e capacidade para $150 \mathrm{~L}$ cada, com sistema de sifão na extremidade inferior para coleta das excretas (sistema de Guelph modificado). Os tanques eram providos de sistema de aeração artificial através de um compressor de ar e aquecimento através de aquecedores de $100 \mathrm{~W}$ quando necessário.

Os animais foram submetidos a um período de adaptação de cinco dias para cada ração avaliada, após esta adaptação, os mesmos eram alimentados por mais dois dias sendo transferidos à noite para os tanques de coleta, os quais retornavam aos tanques de alimentação na manhã seguinte. As fezes dos dois 
tanques de coleta foram retiradas e congeladas, perfazendo uma amostra composta, para cada ração avaliada. Após o período de coleta, os animais ficavam em jejum por um dia, antes da adaptação à próxima ração a ser avaliada.

$\mathrm{O}$ arraçoamento durante o período de adaptação foi realizado à vontade, cinco vezes ao dia, duas no período da manhã e três à tarde. Durante o período de coleta, os animais recebiam ração duas vezes no período da manhã, uma vez no início da tarde, sendo que das $16 \mathrm{~h}$ às $18 \mathrm{~h} 30 \mathrm{o}$ arraçoamento foi realizado a cada 30 minutos. Após 15 minutos da última refeição, os animais foram então transferidos para os tanques de coleta. Sempre após a retirada dos animais, os tanques de alimentação e de coleta de fezes foram lavados.

Os tanques possuíam renovação contínua de água a uma taxa de $50 \%$ do volume total por dia. Os tanques de coleta de fezes, entretanto, não possuíam renovação contínua de água. A água utilizada era clorada e neutralizada através de adição diária de tiossulfito de sódio.

Foram determinados os CDa da MS, PB e EB do farelo de soja (FS), milho (MO), milheto(MT), triticale (TC), farinha de varredura de mandioca (FM), farelo de trigo (FT), trigo (TG) e o CDa da EB óleo de soja (OS). Para determinação da CDa desses alimentos, foi utilizada uma ração-referência purificada (ração 1 da Tabela 1). Os alimentos avaliados foram moídos em um moinho tipo faca com peneira de $0,5 \mathrm{~mm}$, conforme Hayashi et al. (1999), após as dietas-testes e referência foram umedecidas com água a $50^{\circ} \mathrm{C}$ e posteriormente peletizadas em um moinho de carne manual.

As rações-testes (Tabela 1) foram compostas por $70 \%$ da ração-referência e $30 \%$ do alimento a ser testado segundo NRC (1993), sendo corrigido apenas a quantidade de suplemento mineral e vitamínico e sal da mistura de modo a conter $0,5 \%$ em todas as rações. No caso do OS foi formulada uma outra ração purificada sem a presença deste ingrediente (ração 2 da Tabela 1), para ser utilizada como referência para a determinação da energia digestível do OS, sendo esta comparada com a ração 1 da Tabela 1 (teste para o OS).

Para determinação dos $\mathrm{CDa}$, foi utilizada a

Tabela 1 - Composição percentual das dietas-referências e teste utilizadas para a determinação dos coeficientes de digestibilidade aparente de alimentos para a tilápia do Nilo

Table 1 - Percentual composition of reference and test diets used to determine the coefficients of aparent digestibility of feedstuffs for Nile tilapia

\begin{tabular}{|c|c|c|c|}
\hline $\begin{array}{l}\text { Alimentos } \\
\text { Feedstuffs }\end{array}$ & $\begin{array}{l}\text { Ração referência } 1 \\
\text { Reference diet } 1\end{array}$ & $\begin{array}{c}\text { Ração referência } 2 \\
\text { Reference diet } 2\end{array}$ & $\begin{array}{l}\text { Ração teste } \\
\text { Test diet }\end{array}$ \\
\hline Albumina & 32,00 & 32,00 & 22,40 \\
\hline $\begin{array}{l}\text { Albumin } \\
\text { Gelatina }\end{array}$ & 7,70 & 7,70 & 5,39 \\
\hline $\begin{array}{l}\text { Gelatin } \\
\text { Antioxidante BHT } \\
\text { Antioxidant BHT }\end{array}$ & 0,02 & 0,02 & 0,01 \\
\hline $\begin{array}{l}\text { Amido de milho } \\
\text { Corn starch }\end{array}$ & 44,18 & 50,18 & 30,93 \\
\hline $\begin{array}{l}\text { Celulose } \\
\text { Cellulose }\end{array}$ & 6,00 & 6,00 & 4,20 \\
\hline $\begin{array}{l}\text { Fosfato bicálcico } \\
\text { Dicalcium phosphate }\end{array}$ & 3,00 & 3,00 & 2,10 \\
\hline $\begin{array}{l}\text { Óleo vegetal } \\
\text { Vegetal oil }\end{array}$ & 6,00 & 0,00 & 4,20 \\
\hline $\begin{array}{l}\text { Suplemento (min. }+ \text { vit. })^{1} \\
\text { Supplement (min. }+ \text { vit.) }\end{array}$ & 0,50 & 0,50 & 0,50 \\
\hline $\begin{array}{l}\text { Sal } \\
\text { Salt }\end{array}$ & 0,50 & 0,50 & 0,50 \\
\hline $\begin{array}{l}\text { Óxido crômico } \\
\text { Chromic oxide }\end{array}$ & 0,10 & 0,10 & 0,10 \\
\hline $\begin{array}{l}\text { Alimento teste } \\
\text { Test foods }\end{array}$ & 0,00 & 0,00 & 29,67 \\
\hline Total & 100,00 & 100,00 & 100,00 \\
\hline
\end{tabular}


metodologia indireta, tendo como indicador o óxido crômico $\left(\mathrm{Cr}_{2} \mathrm{O}_{3}\right)$, segundo NRC (1993), incorporado na proporção de $0,1 \%$ da ração.

Após o período de coleta, as fezes foram descongeladas, secas em estufa de circulação forçada a $55^{\circ} \mathrm{C}$ por 24 horas, peneiradas para a retirada das escamas e moídas para as análises bromatológicas, realizadas no Laboratório de Análises de Alimentos do Departamento de Zootecnia da Universidade Estadual de Maringá, segundo Silva (1990). Foram analisados também os alimentos e as rações-testes. A análise para a determinação da concentração do cromo, nas fezes e nas rações-testes, foram realizadas no Laboratório de Solos do Departamento de Agronomia da Universidade Estadual de Maringá, determinado por espectrofotometria de absorção atômica, segundo Kimura \& Miller (1957), para posterior cálculo do coeficiente de digestibilidade (NRC ,1993; Mukhopadhyay \& Ray, 1997).

As variáveis $\mathrm{pH}$, condutividade e oxigênio dissolvido foram monitoradas três vezes por semana, enquanto a temperatura foi medida diariamente às $8 \mathrm{~h} 30$ e $16 \mathrm{~h} 30$.

\section{Resultados e Discussão}

Os valores médios de temperatura, $\mathrm{pH}$, oxigênio dissolvido e condutividade elétrica durante o período experimental foram de $25,85 \pm 1,02^{\circ} \mathrm{C} ; 6,79 \pm 0,15 ; 3,18$ $\pm 1,38 \mathrm{mg} / \mathrm{L}$ e $205,72 \pm 16,56 \mathrm{mS} / \mathrm{cm}$, respectivamente, permanecendo dentro da faixa recomendada para a aqüicultura (Boyd, 1990; Sipaúba-Tavares, 1995).

A composição química dos alimentos avaliados para a tilápia do Nilo estão apresentados na Tabela 2.

Os coeficientes de digestibilidade aparente $(\mathrm{CDa})$ da matéria seca (MS) para o farelo de soja (FS), milho (MO), milheto (MT), triticale (TC), farinha de varredura de mandioca (FM), farelo de trigo (FT) e trigo integral (TG) encontram-se na Tabela 3.

Os CDa para a matéria seca MS do FT $(66,79 \%)$, FS $(65,49 \%)$ e do TC $(68,51 \%)$ foram os menores entre os alimentos avaliados; este resultado pode ser explicado pela alta percentagem de polissacarídeos não amiláceos, que compõem esses alimentos, os quais não são aproveitados eficientemente pela tilápia do Nilo e também devido ao fato de alguns desses componentes atuarem como redutores da digestibilidade, como por exemplo, as pentosanas e beta-glucanos presentes no triticale, que causam aumento da viscosidade intestinal prejudicando a ação enzimática (Furlan et al., 1997). Para os demais alimentos avaliados os CDa da MS determinados ficaram acima de 70\%. Os CDa da MS do FS e FT avaliados no presente trabalho são inferiores aos obtidos por Pezzato et al. (1988) de 87,00 e 87,86\%; respectivamente; este resultado pode ser explicado devido à diferença de metodologias utilizadas.

Os CDa da EB e valores de energia digestível

Tabela 2 - Composição química dos alimentos avaliados para a tilápia do Nilo1 Table 2 - Chemical composition of foods available for Nile tilapia

\begin{tabular}{|c|c|c|c|c|}
\hline $\begin{array}{l}\text { Alimentos } \\
\text { Foods }\end{array}$ & $\begin{array}{c}\text { Matéria seca }(\%) \\
\text { Dry matter }\end{array}$ & $\begin{array}{c}\text { Proteína bruta }(\%)^{2} \\
\text { Crude protein }\end{array}$ & $\begin{array}{c}\text { Energia bruta }(\mathrm{kcal} / \mathrm{kg})^{2} \\
\text { Gross energy }\end{array}$ & $\begin{array}{c}\text { Extrato etéreo }(\%)^{2} \\
\text { Crude fat }\end{array}$ \\
\hline $\begin{array}{l}\text { Farelo de soja } \\
\text { Soybean meal }\end{array}$ & 91,86 & 47,25 & 4283,60 & 2,32 \\
\hline $\begin{array}{l}\text { Milho } \\
\text { Corn }\end{array}$ & 90,34 & 7,69 & 3963,24 & 4,27 \\
\hline $\begin{array}{l}\text { Milheto } \\
\text { Millet pearl }\end{array}$ & 90,66 & 14,61 & 4213,74 & 5,82 \\
\hline $\begin{array}{l}\text { Triticale } \\
\text { Triticale }\end{array}$ & 91,11 & 14,50 & 4011,00 & 1,23 \\
\hline $\begin{array}{l}\text { Farinha varredura mandioca } \\
\text { Cassava by-product meal }\end{array}$ & 88,85 & 1,80 & 3588,72 & 0,94 \\
\hline $\begin{array}{l}\text { Farelo de trigo } \\
\text { Wheat meal }\end{array}$ & 90,66 & 14,77 & 4106,78 & 3,65 \\
\hline $\begin{array}{l}\text { Trigo integral } \\
\text { Whole wheat }\end{array}$ & 91,42 & 11,43 & 3932,08 & 2,30 \\
\hline $\begin{array}{l}\text { Óleo de soja } \\
\text { Soybean oil }\end{array}$ & - & - & 9443,83 & - \\
\hline
\end{tabular}

${ }_{1}^{1}$ Análises realizadas no LANA/DZO/UEM (Analysis made in Lana-DZO/UEM).

${ }^{2}$ Valores expressos com base na matéria natural (Values express as fed basis). 
Tabela 3 - Coeficientes de digestibilidade aparente da matéria seca, proteína bruta e energia bruta e valores de proteína energia digestíveis de alimentos de origem vegetal para a tilápia do Nilo

Table 3 - Coefficients of apparent digestibillity of dry matter, gross protein and gross energy and values of digestible energy and protein of vegetable foods for Nile tilapia

\begin{tabular}{lccccc}
\hline & \multicolumn{5}{c}{ Coeficientes de digestibilidade (\%) } \\
Coefficients of digestibility
\end{tabular}

$1,2(\%),(\mathrm{kcal} / \mathrm{kg})$ respectivamente (Valores expressos com base na matéria natural).

1,2 (\%), (kcal/kg) respectivement (Values express as fed basis).

(ED) em $\mathrm{kcal} / \mathrm{kg}$ dos alimentos avaliados, foram de $71,38 \%$ e 3057,$63 ; 76,63 \%$ e 3037,$03 ; 89,12 \%$ e 3755,$55 ; 80,55 \%$ e 3230,$69 ; 91,40 \%$ e 3280,$09 ; 68,81 \%$ e 2825,$88 ; 87,07 \%$ e 3423,66 e $89,85 \%$ e 8485,28 para o FS, MO, MT, TC, FM, FT, TG e OS, respectivamente, Tabela 3.

O FS apresentou CDa da EB de 71,38\%, este valor é superior ao encontrado por Hanley (1987) $(56,58 \%)$ para tilápia do Nilo e inferior aos encontrados por Degani et al. (1997b) (80,62\%) para tilápias híbridas adultas (Oreochromis niloticus x O. aureus), e próximo ao encontrado por Degani et al. (1997a) para carpa (Cyprinus carpio) (74,71\%). O CDa da EB do TG foi de $87,07 \%$, sendo inferior ao encontrado para a farinha de trigo por Degani et al. (1997b) $(96,03)$ e superior ao triguilho avaliado por Hanley (1987) (57,58\%). O CDa da EB do MO foi de $76,63 \%$, valor semelhante ao encontrado por Hanley (1987) $(76,04)$ e inferior ao de Degani et al. (1997b) (82,84).

Com relação à $\mathrm{FM}$, foi determinado o $\mathrm{CDa}$ da $\mathrm{EB}$ de $91,40 \%$, com valor de $3280,09 \mathrm{kcal}$ de ED; valor semelhante ao determinado por Barros et al. (1988) para a tilápia do Nilo $(3293,00)$. Hanley (1987) avaliando a ED do óleo animal encontrou CDa da EB de $93,04 \%$ e valor de ED de $8675,53 \mathrm{kcal} / \mathrm{kg}$, resultado este próximo ao obtido no presente trabalho para oOS que apresentou CDa de $89,85 \%$ e $8485,28 \mathrm{kcal} / \mathrm{kg}$ de ED. O CDa da EB da FM, que é um alimento composto basicamente por amido, foi um pouco superior ao CDa da EB do OS; este fato concorda com Degani $\&$ Revach (1991), onde relatam melhor aproveitamento do amido em relação a lipídeos por esta espécie.

O CDa da energia bruta do FS para a truta, avaliado por Aksnes \& Opstvedt (1998), foi de 56,00\%, e para o TC avaliado por Gomes \& Kaushik (1990), de $75,20 \%$; estes resultados são inferiores aos obtidos no presente estudo, demonstrando que a tilápia do Nilo, por ser um peixe de hábito alimentar onívoro, apresenta melhor aproveitamento da energia de alimentos de origem vegetal quando comparada aos carnívoros.

Os CDa da proteína do FS, MO, MT, TC, FM, FT e TG foram de 89,28; 93,40; 94,91; 94,78; 97,52; 91,00 e $96,30 \%$, respectivamente, Tabela 3 .

Os CDa da PB do FS $(89,28 \%)$ foi inferior ao avaliado para a tilápia por Degani et al. (1997b) $(94,61 \%)$ e próximo aos determinados por Hanley (1987) (90,73\%) para a tilápia, Nengas et al. (1995) para Spauratus auratus $(90,90 \%)$, e Aksnes \& Opstvedt (1998) para a truta $(91,10 \%)$, sendo superior ao encontrado por Degani et al. (1997a) para carpa (Cyprinus carpio) $(69,83 \%)$, e Brown et al. 
(1985) para o bagre do canal (85,00\%). O TG apresentou CDa da PB de 96,30\%, valor este superior ao encontrado por Degani et al. (1997b), para a farinha de trigo $(91,26 \%)$ e superior ao encontrado para o triguilho por Hanley (1987) $(75,63 \%)$ e semelhante ao triguilho para o salmão $(96,20 \%)$ e para a truta $(96,70 \%)$ avaliados por Sugiura et al. (1998). Já o MO apresentou CDa da PB semelhante ao de Degani et al. (1997a) (92,84\%). Entretanto, os CDa determinados para o FS $(89,28 \%)$ e o FT $(91,00 \%)$, quando comparados com os valores obtidos por Pezzato et al. (1988) para o FS $(95,25 \%)$ e FT $(96,25 \%)$ são inferiores. No entanto, os valores determinados para o MO $(95,19 \%)$ e farinha de mandioca $(94,22 \%)$ por Barros et al. (1988) encontram-se mais próximos dos determinados no presente trabalho, porém foi superior ao encontrado para o M por Hanley $(1987)(83,26)$. O TC avaliado para a truta por Gomes \& Kaushik (1990) apresentou CDa da PB inferior (84,80\%).

Com relação aos CDa da PB determinados, podemos verificar que geralmente a tilápia do Nilo, apresenta igual ou superior capacidade de aproveitamento dos alimentos avaliados, com relação aos resultados obtidos por diversos autores, com outras espécies, utilizados como base de comparação.

As diferenças entre os CDa dos trabalhos utilizados para a comparação com o presente experimento podem ser atribuídas a uma série de fatores, como diferenças na metodologia de coleta de fezes (Smith \& Lovell, 1973; Vens-Cappel, 1985; NRC, 1993; Sullivan \& Reigh, 1995), níveis de inclusão do alimento teste, possíveis fatores antinutricionais ou desbalanço aminoacídico (Mukhopadhyay \& Ray, 1997), espécies ou linhagens de animais, de acordo com as diferenças na fisiologia da digestão (Degani et al., 1997), formulação e processamento das rações e alimentos que as compõem (McGoogan \& Reigh, 1996), a variedade do grão cultivado (Fancher et al.,1987; Leterme et al., 1991) e do local e solo em que é cultivado (Owsley, et al., 1987).

Os $\mathrm{CDa}$ da $\mathrm{EB}$ e conseqüentes valores de ED determinados no presente trabalho para os alimentos de origem vegetal avaliados são considerados satisfatórios e podem ser explicados pela eficiência com que a tilápia do Nilo utiliza os carboidratos da dieta, confirmando as citações de Viola \& Arieli (1983), Anderson et al. (1984), Degani \& Revach (1991) e Shiau (1997). Esta é uma característica favorável para o desenvolvimento da criação desta espécie, pois geralmente os alimentos ricos em amido são de menor custo.

\section{Conclusões}

Os coeficientes de digestibilidade aparente da matéria seca, proteína bruta e energia bruta foram de $65,49,89,58$ e 71,38 para o farelo de soja; $73,22,93,40$ e 76,63 para o milho; $86,51,96,30$ e 87,07 para o trigo; $66,79,91,00$ e 68,81 para o farelo de trigo; $77,96,94,91$ e 89,12 para o milheto; $68,51,94,78$ e 80,55 para o triticale; $91,11,97,52$ e 91,40\% para a farinha de varredura de mandioca, respectivamente; e para a energia bruta do óleo de soja, o coeficiente de digestibilidade aparente foi de $89,85 \%$. Apresentando valores de proteína (\%) e energia $(\mathrm{kcal} / \mathrm{kg})$ digestíveis de 42,19 e 3057,63 para o farelo de soja; 7,18 e 3037,03 para o milho; 11,01 e 3423,66 para o trigo; 13,44 e 2825,88 para o farelo de trigo; 13,88 e 3755,55 para o milheto; 13,74 e 3230,69 para o triticale; 1,76 e 3280,09 para a farinha de varredura de mandioca, respectivamente; e 8485,28 kcal $/ \mathrm{kg}$ de energia digestível para o óleo de soja.

Os resultados do presente estudo demonstraram que a tilápia do Nilo utiliza a energia e proteína eficientemente desses ingredientes.

\section{Literatura Citada}

AKSNES, A.; OPSTVEDT, J. Content of digestible energy in fish feed ingredients determined by the ingredient-substitution method. Aquaculture, v.161, p.45-53, 1998.

ANDERSON, J.; JACKSON, A.J.; MATTY, A.J. et al. Effects of dietary carbohydrates and fiber on the tilapia, Oreochromis niloticus (Linn.). Aquaculture, v.13, p.265-272, 1984.

BARROS, M.M.; PEZZATO, L.E.; SILVEIRA, A.C. et al. Digestibilidade aparente de fontes energéticas pela tilápia do Nilo (Oreochromis niloticus). In: SIMPÓSIO LATINOAMERICANO, 6., SIMPÓSIO BRASILEIRO DE AQÜICUlTuRA, 5., 1988, Florianópolis. Anais... Florianópolis: SIMBRAq, 1988. p.433-437.

BOYD, C. Water quality in ponds for aquaculture. London: Birmingham Publishing, 1990. 482p.

BROWN, P.B.; STRANGE, R.J.; ROBBINS, K.J. Protein digestibility coefficients for yearling channel catfish fed high protein feedstuffs. The Progressive Fish-Culturist, v.47, n.2, p.94-97, 1985.

CHO, C.Y. Digestibility of feedstuffs as a major factor in aquaculture waste management. In: KAUSHIK, S.J.; LAQUET, P. (Eds.) Fish nutrition practice. Paris: INRA, 1993. p.363-374.

DEGANI, G.; REVACH, A. Digestive capabilities of three commensal fish species: carp, Cyprinus carpio L., tilapia, Oreochromis aureus $X O$. niloticus, and African catfish, Clarias gariepinus (Burchel 1822). Aquaculture Fish Management, v.22, p.397-403, 1991.

DEGANI, G.; VIOLA, S.; YEHUDA, Y. Apparent digestibility coefficient of protein sources for carp (Cyprinus carpio L). Aquaculture Research, v.28, n.1, p.23-28, 1997a. 
DEGANI, G.; VIOLA, S.; YEHUDA, Y. Apparent digestibility of protein and carbohydrate in feed ingredientes for adult tilapia (Oreochromis aureus X O. niloticus). The Israeli Journal Aquaculture, v.49, n.3, p.115-123, 1997 b.

EL-SAYED, A.F.M. Alternative dietary protein sources for farmed tilapia, Oreochromis spp. Aquaculture, v.179, p.149-168, 1999.

FANCHER, B.I.; JENSEN, L.S.; SMITH, R.L. et al. Metabolizable energy contends of pearl millet (Pennisetum americanum L.). Poultry Science, v.66, p.1693-1696, 1987.

FURLAN, A.C.; FRAIHA, M.; MURAKAMI, A.E. et al. Utilização de Complexo Multienzimático em Dietas de Frangos de Corte Contendo Triticale. Ensaio de Digestibilidade. Revista Brasileira de Zootecnia, v.26, n.4, p.759-764, 1997.

GOMES, E.F.; KAUSHIK, S.J. Potential use of triticale in diets for rainbow trout: effects of dietary levels and incidence of cooking. Animal Zootechny, v.39, p.63-73, 1990.

HANLEY, F. The digestibility of foodstuffs and the effects of feeding selectivity determinations in Tilápia (Oreochromis niloticus L). Aquaculture, v.66, n.2, p.163-179, 1987.

HAYASHI, C.; BOSCOLO, W.R.; SOARES, C.M. et al. Uso de diferentes graus de moagem dos ingredientes em dietas para a tilápia do Nilo (Oreochromis niloticus L.) na fase de crescimento. Acta Scientiarum, v.21, n.3, p.733-737, 1999.

JONES, P.L.; DE SILVA, S.S. Apparent nutrient digestibility of formulated diets by the Australian freshwater crayfish Cherax destructor Clark (Decapoda, Parastacidae). Aquaculture Research, v.28, n.11, p.881-891, 1997.

KIMURA, F.T.; MILLER, V.L. Improved determination of chromic oxide in cal feed and feces. Journal Agriculture Foodstuffs Chemistry, v.5, n.2, p.216, 1957.

LETERME, P.; TAHON, F.; THEWIS, A. Nutritive value of triticale cultivars in pigs as function of their chemical composition. Animal Feed Science and Technology, v.35, n.1, p.49-53, 1991.

LOVSHIN, L.L. Tilápia farming; a growing worldwide aquaculture industry. In: SIMPÓSIO SOBRE MANEJO E NUTRIÇÃO DE PEIXES, 1997, Piracicaba. Anais... Piracicaba: Fundação de Estudos Agrários “Luís de Queiroz”, 1997. p.137-164.

MCGOOGAN, B.B.; REIGH, R.C. Apparent digestibility of selected ingredients in red drum (Sciaenops ocellatus) diets. Aquaculture, v.141, p.233-244, 1996.

MORALES, A.E.; CARDENETE, G.; SANZ, A.; et al. Reavaluation of crude fiber and acid-insoluble ash as intermarkers, alternative to cromic oxide, in digestibility studies with rainbow trout (Oncorhynchus mykiss). Aquaculture, v.179, p.71-79, 1999.

MUKHOPADHYAY, N.; RAY, A.K. The apparent total and nutrient digestibility of sal seed (Shorea robusta) meal in rohu, Labeo rohita (Hamilton), fingerlings. Aquaculture Research, v.28, p.683-689, 1997.

NATIONAL RESEARCHCOUNCIL-NRC. Nutrient requirements of warmwater, fishes and shellfishes: nutrient requirements of domestics animals. Washington, D.C.: 1993. 114p.

NENGAS, I.; ALEXIS, M.N.; DAVIES, S.J. et al. Investigation to determine digestibility coefficients of various raw materials in diets for gilthead sea bream Spauratus auratus L. Aquaculture Research, v.26, p.185-194, 1995.
NOÜE, J.; CHOUBERT, G. Digestibility in rainbow trout: comparison of the direct and indirect methods of measurement. The Progressive Fish-Culturist., v.48, p.190-195, 1986.

OWSLEY, W.F.; HAYDON, K.D.; LEE, R.D. Effect of variety and planting location on the value of triticale for swine. Journal of Animal Science, v.65, n.1, p.37, 1987.

PEZZATO, L.E.; PEZZATO, A.C.; SILVEIRA, A.C. et al. Digestibilidade aparente de fontes protéicas pela tilápia do Nilo (Oreochromis niloticus). In: SIMPÓSIO LATINOAMERICANO, 6., SIMPÓSIO BRASILEIRO DE AQÜICUltura, 5., 1988, Florianópolis. Anais... Florianópolis: SIMBRAq, 1988. p.373-378.

PEZZATO, L.E. Alimentação de peixes - Relação custo benefício. In: REUNIÃO ANUAL SOCIEDADE BRASILEIRA DE ZOOTECNIA, 37., 1999, Porto Alegre. Anais... Porto Alegre: Sociedade Brasileira de Zootecnia, 1999. p.109-118.

SADIKU, S.O.E.; JUANCEY, K. Digestibility, apparent amino acid availability and waste generation potential of soybean flour: poultry meat meal blend based diets for tilapia, Oreochromis niloticus (L.), fingerlings. Aquaculture Research, v.26, p.651-657, 1995.

SHIAU, S.Y. Utilization of carbohydrates in warmwater fish with particular reference to tilapia, Oreochromis niloticus x O. aureus. Aquaculture, v.151, p.79-96, 1997.

SILVA, D.J. Análise de alimentos (Métodos químicos e biológicos). Viçosa, MG: Universidade Federal de Viçosa, 1990. 166p.

SMITH, B.W.; LOVELL, R.T. Determination of apparent protein digestibility in feeds for channel catfish. Transaction of the American Fisheries Society, v.4, p.831-835, 1973.

SIPAÚBA-TAVARES, L.H.S. Limnologia aplicada à aqüicultura. Jaboticabal: Funep, 1995. 72p.

SUGIURA, S.H.; DONG,F.M.; RATHBONE, C.K. et al. Apparent protein digestibility and mineral availabilities in various feed ingredients for salmonid feeds. Aquaculture, v.159, p.177-202, 1998 .

SULLIVAN, J.A.; REIGH, R.C. Apparent digestibility of selected feedstuffs in diets for hybrid striped bass (Morene saxatilis x Morene chrysops). Aquaculture, v.138, p.313-322, 1995.

VENS-CAPPEL, B. Methodical studies on digestion in trout. 1. reliability of digestion coefficients in relation to methods for feces collection. Aquaculture Enginering, v.4, p.33-49, 1985.

VIOLA, S.; ARIELI, Y. Evaluation of different grains as ingredients in complete feeds for carp and tilapia in intensive culture. Israel Journal Aquaculture, v.35, p.38-43, 1983. 